\title{
Implementation of Logistics enterprises' Brand Competition Strategy in China
}

\author{
CHEN Ping ${ }^{1, a} \quad$ KUANG $M^{2, b}$ \\ 1.CHEN Ping, Foshan Polytechnic, Foshan 528137, PRC. \\ chenping_802<18202077989@163.com \\ 2.KUANG Mo, Business School of Guangzhou University, Guangzhou510006, PRC. \\ Kuangmo-169@263.net
}

Keyword: brand competition, present situation analysis, strategy selection,

\begin{abstract}
In the process of economic globalization, logistics enterprises in China find it importance to brand competition and brand integration for improving their competitiveness. A company cannot gain solid position in market competition, without making brand core value, designing a series of strategy and carry out. This study analyzes the present situation of logistics enterprises in China, offers a proposal about how to bring the brand strategy into effect.
\end{abstract}

\section{Summary of brand competition}

It is a long history since the first brand come up. The brand concept emerged from brick-maker in the ancient Egyptian to European brewers in the $16^{\text {th }}$ century. The brand name began to be distinguish products from others in the market. AMA gave a definition of a brand as a name, term, sign, symbol, or design, or a combination of these, intended to identify the goods or services of one seller or group of sellers and to differentiate them from the competition. Actually, the meaning of brand now is far more than that. It links the modern companies in the society with their whole images and brand. A good product wins a good reputation as a brand, which will make the customers interested in other products of the company. And the whole company finally enjoys the trust in society through its successful brand. In other words, it is the modern brand strategy focusing on a core brand creation, then achieving the brand image of the company, taking advantage from it, with which fights for market share.

The brand strategy is an important operation strategy for company development in market-oriented economy conditions. In the background of globalization, competition becomes the theme. Nowadays, we all know the importance of brands for logistics enterprises' survival and development. Brand strategy has become a magic weapon for many well-known companies to gain solid position in market competition. How to improve competitiveness of logistics enterprises is crucial to them. Firstly, the awareness of competitiveness should be improved. Secondly, proper development countermeasures should be prepared. Thirdly, additional effort should be worked on product features, management, and staff quality. In these ways, the comprehensive competitive advantage of logistics enterprises can be improved.

After preparing a complete brand strategy, logistics enterprises should correctly realize their own competitiveness, and then use the brand strategy to improve. Determine the production location reasonably, and implement appropriate development strategies. The current market conditions show that supply is larger than demand. And the customers' requirement is diversified, differentiated, and varied. Thus, it is no logistics enterprise that can make its products to satisfy all customers and occupy the whole market whatsoever its range and scale. Therefore, positioning logistics enterprises appropriately and determining to develop brand strategy are prerequisites for improving competitiveness.

Many well-known logistics enterprises in the world regard brand development as the preferential strategy for them to explore the international market. Such as UPS and FedEx start from the brand strategy, create their own brands, and take it as a method for market exploration and occupation The branding strength is enormous and its market influence is quite significant. Therefore, after a brand 
is created, a series of brand-related products will be formed gradually and related industries will be developed. Brands are weapons for logistics enterprises to enter and occupy the market. In addition, in the development of logistics enterprises, a brand is closely connected with the price of products, product prices always affect the sales revenue and profit of the logistics enterprise. Brand is an invisible tool to determine product price other than product features, technical contents, and applications. In 2011, the sales revenue of Apple's brand was increased by 58\%, and the sales amount of world's top 20 brands took 4.0418 trillion USD. Meanwhile, the profit rate of these brand products is much higher than that of normal brand products. Take the sales price as an example: For the same type of products, the sales price of the branded product is times higher than normal product. Therefore, a brand is large intangible asset and tremendous wealth to a logistics enterprise. In the field of trade, merchants choose products of a certain brand because it normally represent quality wanrranty. Good quality leaves reputation to consumers, this brand is valuable. Even if its selling price is much higher than that other non-branded product, consumers still purchase it and take its high price as a noble status symbol. Like "Apple" in the computer industry, and "Rolls-Royce" and "Ferrari" in the automobile industry, branding can bring a lot of profit to logistics enterprises.

\section{Analysis of the brand competition of logistics enterprise in China}

\section{A. The flow of building brand of logistics enterprise}

It is a long term investment for brand building, which asks a lot of input during processes of developing, marketing, communicating and servicing from the logistics enterprise.

Base on analysis of customers' requirements and market situations, logistics enterprises should position their brands by their strength, then promote it with market communication and services. The characteristics of branding should be outstanding, lasting, systematizing, globalizing and comprehensive. Therefore, it requires that logistics enterprises implement long-term operation from a strategic perspective by overlooking the overall situation. It cannot be achieved on temporary basis.

Logistics enterprises branding can be successfully achieved if being combined with a variety of management and marketing strategies, being divided into some implementation phases and operated by experienced managent. And the whole branding strategy should have processes of Brand Creating, Brand Marketing and Brand protecting as below (Chart 1.).

\section{B. The situation of logistics enterprises' brand competition in China}

Since the reform and opening up, China's economy has experienced decades of rapid growth. With the continuous expansion of economy, China market has become an important part of the international market. There is a great change for domestic logistics enterprises to participate in international competition. The world-kowned logistics enterprises implement their brand strategies in an increasingly competitive and complex market in China, and Chinese brands are facing severe challenges of international competition. Especially after joining the WTO, most logistics enterprises in China would be in head-to-head competition with powerful foreign competitors, and more and more foreign famous brands would enter the market. Facing this unprecedented brand impact, logistics enterprises in China can only implement brand strategies to create brand logistics enterprises and branded products. Only in this way can they enter the international market, gain advantages in the competition, and compete against with foreign brands. On the other hand, with the progress of science and technology, consumer requirement becomes more diversified. As a result, logistics enterprises implementing brand strategies can not only enlarge their market share, but also obtain greater economic benefits. In addition, logistics enterprises in China still have a long way to go in the brand competition. In the current market-oriented economy, the brand competition other than the price competition is the highest level, which avoids the endless price reduction, discount, and gifts. In addition, the price competition does harm not only to competitors but also to logistics enterprises themselves. At present, main problems occurred from brand competition among logistics enterprises in China are as follows: 


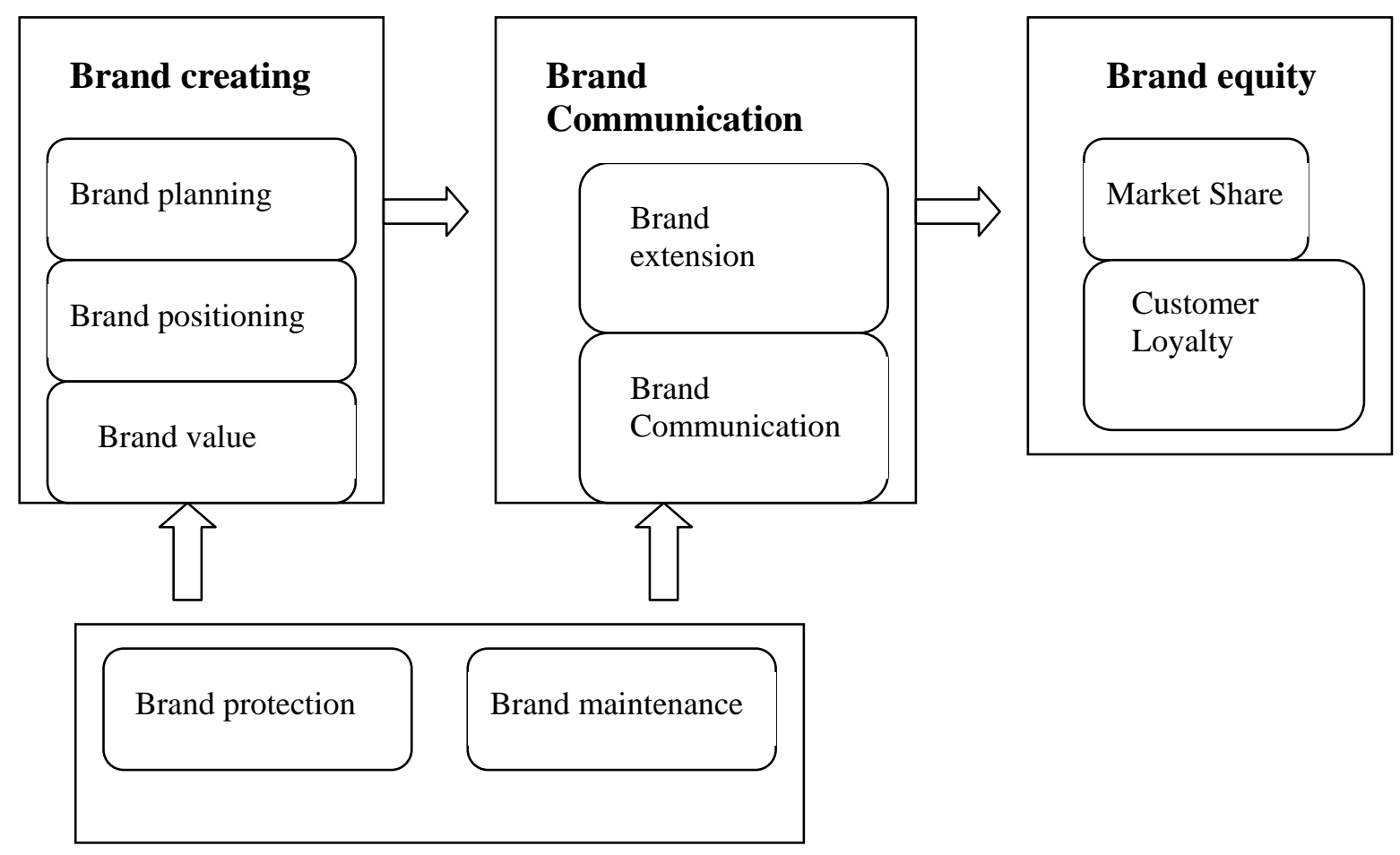

\section{Chart 1. The flow of brand building}

(1) Lack of awareness of brand: Most logistics enterprises regard brand as awareness. They believe that the brand effect can be created only if a lot of money is invested on promotion. Secondly, some logistics enterprises believe that a good brand can be created only if a good company name is offered, a company logo is used, and a well-known spokesman for the image is adopted. For both above methods, the former will only waste a large number of company's economic resources or even do harm to the brand; the later regards the brand as a kind of symbol or logo.

(2) Lack of powerful support of quality and technology: At present, there is no development capability for core technologies for many industries in China. Core products are obtained through import, which is an important reason for Chinese brands having a low competitiveness at home and abroad. Moreover, in the case of backward technical level, domestic logistics enterprises invest heavily in advertising campaign to "create" brand, but not by strengthening technological innovation and management step by step. On the contrary, the real "brand" wins the competition based on its good quality.

(3) Unreasonable brand extension: Many successful high-quality brands fail because of their blind brand extension regardless of good operation over years. With brand recognition by consumers, other brand-related products go to the market quickly, bringing a huge profit for logistics enterprises. However, some logistics enterprises excessively pursue diversification of products. When the main business does not reach to certain size, overly enlarge business range harms. As a result, they cannot obtain consumers' recognition in each field because of their dispersed strength. Unfortunately, they even loose their original advantages.

(4) Lack of core value with regard to the brand: For a brand, its core value is its soul. If there is no clear core value for a brand, it cannot become a mighty brand. However, the core value is the extreme pursuit of a brand, which is the basis for brand marketing activities. Activities implemented by logistics enterprises should focus on the core value. A lot of brands in China advertise without essential value proposition and the topic changes frequently. Although a large number of advertisement are helpful in selling products, but no brand image is accumulated.

(5) Frequently changing the brand image: In the brand communication, many logistics enterprises change their brand images frequently due to lack of deep awareness of the brand, and finally cannot establish a mighty brand. Consistency of the brand image is sustainable weapon for 
some international brands to success. For example, Pepsi-Cola changes its packaging and image spokesperson constantly, but "Choice of new generation" never changes. Thus, a distinct brand image is established.

\section{Path for Logistics enterprises' Brand Competition in China}

Based on the market environment, operation conditions, and competition ability, logistics enterprises must choose a brand competition path that is helpful for company's development, by combining with competition path features of different brands (adopting good points and avoiding shortcomings). At the beginning of the establishment of a logistics enterprise, it can adopt the own brand competition path; at the growth stage, it can adopt the co-branding competition path; at the mature stage, it can adopt the acquiring/merging brand competition path. There are three brand competition paths for logistics enterprises in China:

(1) Self-own brand competition path: The principle of this path is to create the owned brand step by step, gradually expanding the market share and enlarging the brand impact. Its brand expansion progress follows the local brand, domestic brand, and international brand; its geographical expansion progress follows the local market, national market, adjacent overseas markets, and global market. The step for creating this path is as follows: Logistics enterprises firstly develop products with their own features in the domestic market, and create their own brands based on good quality and service; then put the brand into the international market in the international operation through operation range extension, to create the international brand. The disadvantage to create an international brand using this method is taking a long time and requires numerous capital investments.

(2) Co-branding competition path: The co-branding is a form of cooperation between two or more companies belonging to different logistics enterprises. Through brand cooperation, a brand can enrich its exploration through association with other brand, which can create much more and greater value. In 1991, to defend competitors, Intel launched the Pentium chip, and prepared a promotion plan with a huge cost to encourage computer manufacturers to use "Intel Inside" logo on their products. A 3\% discount was offered to those manufacturers participating in this plan, and a $5 \%$ discount was offered to those manufacturers adding "Intel Inside" logo on their packaging. Computers such as IBM and DELL sold on the market were added with "Intel Inside" in addition to their own brands. In the next year, the sales amount of Intel Company increased by 63\% compared with that of the last year, which was a great success.

The co-branding competition path adopts creating a certain reputation based on others' strength, and then creating its own brand when the time is mature. Therefore, before selecting co-branding mode, a logistics enterprise should be cautious of the other brand's features and operation conditions, avoiding possible operation risks.

(3) Acquiring/Merging brand competition path: it refers that a logistics enterprise merges other logistics enterprises' brand ownership and has the right to use this brand equity. The brand merging includes a famous brand merging a non-famous brand, a large brand merging a small brand, and a mighty brand merging a weak brand. Brands are focused through rules of the market, which is an important strategy for logistics enterprises to implement brand expansion and brand operation.

Merging brands is a good way to enter the international market, especially the developed markets in Europe and the United States, but there is still a great risk. Logistics enterprises select this path should consider the following aspects:

- The consistency between brand market localization and the development strategy of the logistics enterprise

- Company's ability to control

- Potential financial risks

- Culture integration of both companies

If the post-merging cannot create synergy effect, or lose resources due to operation integration, the brand value is difficult to be maintained and improved, and even the original competitive advantages will be lost. This path is more suitable for logistics enterprises who have experience for international market operation with strong financial strength and talents for multinational operation. 


\section{Implementation of Logistics enterprise's Brand Competition Strategy in China}

The brand is a kind of products or services provided by one or a group of salespersons, which is a terminology for distinguishing with other competitors. It represents the image of a logistics enterprise and ensures the product quality, which has the exclusive trademark rights protected by laws, in order to protect from illegal competition. It helps consumers to identify goods, and acts as a guide in the actual purchase process. Meanwhile, a familiar brand name is a kind of "reassurance", ensuring consumers' interests. Whether a country, a region, or a logistics enterprise has its own mighty brand or famous brand becomes the standard to determine whether the economic is developed. It is the reflection of overall strength. Therefore, creating, cultivating, and developing famous brands have become a long-term development strategy for a logistics enterprise, government, and even a country.

(1) Establishing a strong brand operation and strategy concept: Logistics enterprise management should continuously learn modern business knowledge, get to know the business development trend at home and abroad, establishing a strong awareness of the brand development strategy. They should also grasp the opportunity to implement their own brand strategy with a high degree of political responsibility and urgency. A profound understanding and implementation of the brand strategy is fundamental to capture market share for logistics enterprises to seek survival and development.

(2) Positioning the market correctly and determining the strategic brand: Market positioning refers that logistics enterprises differentiate their competitors in the target market through a certain method by providing certain products and services. In this way, the company image is established with favorable competitive position. To implement the brand strategy under the background of homogenization of products in the commercialized mass production, logistics enterprises should develop one or two brands focused on special fields to reflect the specialty based on their actual conditions through market investigation. However, this specialty should be developed based on consumers' requirements, which means it should keep up with the market. For example, Coca-Cola and Pepsi in the beverage industry; Rolex watches in the luxury products; Bentley and Rolls-Royce in the automobile industry, which are successful, being worth study by logistics enterprises.

(3) Using capital operation to accelerate the development: Lack of development funds is a problem for logistics enterprises to implement and promote their brand strategies at present. However, it is not wise stopping spending. The current international practice is to accelerate the pace of brand development through capital operation. The capital operation is to introduce current brands at home and abroad through merging, acquisition, transfer, franchise, and compensation. Creating a brand is the early stage for brand development, and operating the brand is the high level stage for brand development. It should be emphasized that a concept of capital operation is required. When purchasing good brand meeting market requirements, it helps obtaining a good market.

(4) Performing portfolio management using the information network: Once a brand is developed, it should be put on the Internet as soon as possible. Because it is the information age, you can achieve the fastest portfolio management through the information superhighway. Firstly, a newly developed brand is put on the Internet rapidly, which can not only enter the start-up stage, promotion and market exploration, but also reduce the investment that is necessary to make advertisements. This investment, an enormous amount, is necessary for developing any new product. Secondly, information of new products is displayed on the Internet, partners can be found at a most broad view. Thirdly, with the popularity of information networks, shopping online will become a convenient channel, which in turn becomes part of most direct combination of portfolio management. Therefore, the information network should be used for implementing brand strategies.

(5) Adopting large-scale, intensive, and standardized operation management: The brand strategy itself is a kind of large-scale and intensive operation. Firstly, extend and expand the developed brands, and then perform large-scale and intensive operation. In fact, when the newly developed brand enters the start-up stage, it can be pushed into chain operation, regardless of the chain of the logistics enterprise or franchising chain. Secondly, promote the newly developed brand relying on a large group. Thirdly, to implement brand strategies, logistics enterprises perform large-scale and intensive operation on new brand's process through the brand determination process and supervision process. With the growth of technology, the global industry is progressing on standardized operation. At present, the management technologies and management systems of Chinese brands are not 
sophisticated, lack of awareness importance data management importance. Furthermore, the human resource is not enough, lacking of talents meeting internationalized standards fails to meet general standard on the business reputation globally. The concept of Chinese logistics enterprises' culture, operation management, and operation should correspond to the concept and philosophy prevailing in the market-oriented economy. In this way, obstacles of Chinese brands in the technology, project, and trade cooperation can be excluded effectively. All these are problems that logistics enterprises in China should solve in the urgent need for internationalization.

(6) Creating a good logistics enterprise culture atmosphere and development environment: It is not an easy task for logistics enterprises to implement and promote brand strategies. Encouraging employees, making them stable, and introducing talents are important factors. When the brand strategy is created, suggestions corresponding to logistics enterprises' culture become much more important. This decision should be implemented among all employees, and every one should be motivated to participate in shaping the spirit and culture of logistics enterprises. In addition to the internal environment of logistics enterprises, there should be a favorable external environment. Especially for China just adopting the market-oriented economy, it is impossible without government interference at the early stage. To implement and promote brand strategies, logistics enterprises should strive to get government's policy support, which is required. They should also strive to develop in a favorable market environment. Based on coordination by relevant government departments, the "wall" such as conservative, monopoly, and separatism should be eliminated. At last, seek protection by law. The brand development is the real intellectual property, that is, knowledge-based economy which would be aborted or lost without protection by law. Therefore, the other important work for implementing brand strategies is to create a protection environment by law for the intellectual property based on government's support.

(7) Efficient and excellent team support: Logistics enterprises can establish a good team from the following aspects:

a) Enhance the awareness of brand strategy to win and full strategic thought.

b) Establish the concept of innovation which requires all employees to update their thought at any time.

c) Prepare a long-term blueprint to determine development objectives of logistics enterprises.

d) Prepare a detailed implementation plan and carry out the current work based on the preceding plan.Establish a learning-oriented logistics enterprise to continuously learn advanced management and technologies, allowing the logistics enterprise to deal with competition more easily.

\section{References}

[1] Xiaohua SHI, Fanxin WANG; (2008.10) Analysis on How to Bring Branding Strategy into Effect, Branding Strategy Implement, Qilu Culture Construction Forum

[2] Xiuwen ZHANG; (2007.12) Analysis on How to Practice the strategy of Domestic Logistics enterprise, Inner Mongolia Radio and TV University Publisher

[3] Yonggao SONG; (2003) Branding Strategy Management, Zhengjiang University Publisher

[4] Xihuai YANG, Jiang WANG (editor); (2010) Logistic Strategy Management, Higher Education Publisher, Beijing

[5] Qiuli QIN; (2005) Some Successes and Myths in Core Competitive Mode, Chinese Textile Publisher, Beijing,

[6] David A., Branding Management Role, Inner Mongolia Publisher

[7] Kuang MO,(2009.07) Analysis on the Present Construction of Logistics Parks in China, ASCE

[8]Kuang MO,(2010) Discussion on the Present and Countermeasure of Logistics Park in Chinese Perl River Delta region, Guangzhou University Study News (11)

[9] Kuang Mo,(2010) Analysis on How to Update Service System of Logistics enterprise in Our Country, Economy System Innovation (5)

[10] Kuang MO,(2011.07) Analysis of coordination mechanism of the supply chain management in a position of pricing power of demand-side, ICTE2011 